\title{
Determinants of Adoption of Improved Bread Wheat Production Technology in Southern Ethiopia
}

\author{
Tamirat Gizaw Deboche (M.Sc.) \\ Faculty of Environment, Gender and Development Studies, College of Agriculture, Hawassa University, \\ Ethiopia P.O.BOX 05, Hawassa, Ethiopia \\ Deribe Kaske Kacharo (PhD)* \\ Faculty of Environment, Gender and Development Studies, College of Agriculture, Hawassa University, \\ Ethiopia. P.O.BOX 05, Hawassa, Ethiopia \\ Berhanu NegaWasihun $(\mathrm{PhD})$ \\ Faculty of Environment, Gender and Development Studies, College of Agriculture, Hawassa University, \\ Ethiopia. P.O.BOX 05, Hawassa, Ethiopia
}

\begin{abstract}
Bread wheat (Triticum aestivum L.) is one of the major staple and cash crops for smallholder farmers in Ethiopia and is mainly grown in the central and southeastern highlands of the country. Adoption of improved agricultural technologies is one of the most important issues to insure food self-sufficiency as well as food security. However, the adoption and dissemination of improved agricultural technologies are constrained by many factors. The aim of this study was to examine factors affecting adoption and intensity of adoption of improved bread wheat production technology. Multistage sampling techniques were employed. Using a systematic random sampling technique, 168 household heads were taken as sample respondents. Structured interview schedules, focus group discussions, and key informant interviews were used as primary data collection instruments. Data analysis was done using descriptive statistical analysis; mainly Chi-square test, F-test, and Pearson correlation were employed. A Tobit econometrics model was also employed with the help of statistical software. The results revealed that household heads sex, level of education, active labor force members, total land holding size, access to credit, participation in training, exposure to mass media, and frequency contact of extension agents were found to have a significant influence on adoption and intensity of adoption of improved bread wheat production technology. The overall finding of this study underlines the importance of institutional support in the areas of extension services and facilitating access to credit in order to enhance the adoption of new technologies. Therefore, the bureau of agriculture and other development practitioners should give focus to strengthening institutional support to improve the adoption of bread wheat technology.
\end{abstract}

Keywords: Adoption, Technology, Bread Wheat, Tobit model

DOI: $10.7176 /$ FSQM/97-07

Publication date:May $31^{\text {st }} 2020$

\section{INTRODUCTION}

Agriculture plays a significant role in the nourishment of human kind in history and continues to have a golden share in reducing poverty through the use of new technologies. Agriculture is the backbone of Ethiopian economy. This particular sector determines the growth of all other sectors and, consequently, the whole national economy. It constitutes over $50 \%$ of the gross domestic product (GDP), accounts for over $85 \%$ of the labor force and earns over $90 \%$ of the foreign exchange (Alemu, 2010). On average, crop production accounts up 60\% of the sector's outputs, whereas livestock accounts for $27 \%$ and other areas contribute $13 \%$ of the total agricultural value added. The sector is dominated by small-scale farmers who practice rain-fed mixed farming by employing traditional technology, adopting a low-input and low-output production system. The land tilled by the Ethiopian small-scale farmer accounts for $95 \%$ of the total area under agricultural use, and these farmers are responsible for more than $90 \%$ of the total agricultural output (Gebreselassie and Bekele, 2010; Welteji, 2018).

Technology adoption refers to the utilization of new technological inputs and enhancing agricultural productivity. New technology adoption is a decision-making process in which an individual goes through a number of mental stages before making a final decision to adopt or reject an innovation. The decision-making process is the process through which an individual passes from the first knowledge of an innovation, to forming an attitude toward an innovation to make a decision to adopt or reject implementation of new ideas, and confirmation of the decision (Ray, 2001).

Increasing crop production and productivity is essential to achieving food security and supplying inputs for the industrial development sector. Small landholder farmers have the largest share of cereals, around $98 \%$ of products, and the remaining two percent are produced by commercial farms mainly for seed purposes (GAIN, 2013). Therefore, agricultural intensification is an important technique to increase farm productivity with limited 
resource access in smallholders through new agricultural technology innovation and application.

Bread wheat (Triticum aestivum L.) is one of the major staple and cash crops for smallholders in Ethiopia. Mainly, it is grown in the central and southeastern highlands of Ethiopia during the rainy season (June to September) and harvested in October -- November. It is an important cereal crop with an annual production of about 4.22 million tons cultivated in an area of 1.66 million hectares (CSA, 2016). Ethiopia is the second largest wheatproducing country in Africa next to South Africa (GAIN, 2014). However, the country imports wheat every year from abroad because of the low level of wheat production and the high demand from consumers.

In Ethiopia, there are 16 major wheat producing zones in the four regions they have been account for $83 \%$ of the country wheat production. Eight zones from the Oromia region (West Shewa, North Shewa, East Shewa, Arsi, Bale, South West Shewa, Horoguduro, and West Arsi); six zones from the Amhara region (North Gonder, South Gonder, South Wollo, North Shewa, East Gojjam, and West Gojjam); the South West Tigray Zone from Tigray Region and Hadiya zone from the South Nation Nationalities and Peoples Region (ECXA,2008).

Adopting full wheat production packages such as row planting, improved bread wheat varieties, seeding rate, fertilizer amount, time of fertilizer application, time of weed control, space between rows, and plowing frequency have been increasing wheat yield in Ethiopia (Tolesa et al., 2014). According to UNDP (2014), supporting of an agricultural transformation agency is one of the strategies to improve wheat productivity in Ethiopia, and a new direct seed marketing approach was introduced and implemented in 70 Districts' in Oromia, Amhara, SNNPR, and Tigray regional state. Agricultural extension services have been focused on the promotion, adoption, and scaling up of wheat production technology adoption.

Agricultural intensification is an important technique to increase farm productivity with limited resource access. Thus, agricultural intensification could be defined in terms of increasing labor and capital inputs per unit area, substitution of commercially important varieties of seeds and farm implements, and adopting new technologies. Agricultural extensification refers to increasing agricultural production by cultivating additional land. Expansion of farmland and intensification or use of more inputs and new technologies per unit of land are the two possible ways of increasing agricultural productivity. A higher agricultural yield could be obtained by the use of inputs per unit of land and expanding cultivable farmland in the agricultural sector (Berihun et al., 2014). However, in the study area context, land scarcity is prominent and intensification is essential to improve wheat productivity.

In Ethiopia, the main problems facing agriculture are low productivity, low use of improved farm inputs, and dependency on rain-fed agricultural production (Lulit et al., 2012). Wheat is one of a major crop with low yield and high demand. Low utilization of improved farm inputs and low adoption of improved bread wheat production technologies made yields of bread wheat became low. However, wheat covers around $15.81 \%$ of the total cereal area with an average national yield of $25.35 \mathrm{q} / \mathrm{ha}$. The productivity is very low compared to the world average of $40 \mathrm{q} / \mathrm{ha}(\mathrm{FAO}, 2009)$.

Low productivity made the country unable to meet the high demand and instead of increasing wheat productivity by applying improved inputs and agricultural practices, the country is a net importer of wheat (Tolesa, 2015). To feed the rapidly growing population and to meet the high demand, smallholders need to increase wheat productivity through the adoption of improved agricultural technologies. Wheat production technology Innovation and adoption is essential to increase wheat yield in Ethiopia. The agricultural and natural resource development sector has been scaling up and promoting the row-planting technique.

Hadiya zone is one of the wheat-producing potential areas in southern Ethiopia. The total land covered by wheat crops is 37,149 hectares and average productivity is $27.5 \mathrm{q} / \mathrm{ha}(\mathrm{CSA}, 2016)$. However, the adoption level of wheat production technology and the determinant factors that affect wheat production have not been studied in the research area. Therefore, the current study was conducted to generate information on these gaps with the aim of assessing the adoption level of improved bread wheat production technology and to analyze factors that influence improved bread wheat production technology adoption.

\section{RESEARCH METHODOLOGY}

\subsection{Description of the study area}

The study was conducted in the Hadiya Zone, Anilemo District, which is geographically located between $7^{0} 35^{\prime}$ $7^{0} 40^{\prime}$ North latitude and $37^{0} 55^{\prime}-38^{0} 06^{\prime}$ East longitude (CSA, 2011). Anilemo District is about $214 \mathrm{~km}$ away from Addis Ababa, the capital city of Ethiopia. The total area of the District is 20,566 hectares of which 15,650 cultivated land, 1,765 perennial crops, 568 covered by natural forest, and 583 grazing land. The District's mean annual rainfall ranges from 1000-1200 mm.

\subsection{Research Design}

The researchers used a cross-sectional survey method with a mixed approach of research method that involves both qualitative and quantitative methods. 


\subsection{Sampling techniques and sample size}

Multistage sampling techniques were employed. In the first stage, Anilemo District was selected because of its better performance in the application of improved bread wheat production technologies among ten districts in the zone. In the second stage, two administrative villages were selected based on improved bread wheat production technology application performance and wheat production potential. In the third stage, 168 farm household heads were selected randomly using a systematic random sampling technique.

\subsection{Type of data, sources, and method of data collection}

Both quantitative and qualitative types of data were collected from primary and secondary sources. Primary data were gathered using a survey questionnaire, Focus Group Discussions (FGD), and Key Informant Interview (KII). A pretest of survey questionnaires was conducted on selected non-sample household heads.

\subsection{Methods of Data Analysis}

Both descriptive and inferential statistical techniques were used for analytical purposes. Qualitative data were analyzed using narrating and explaining farmers improved bread wheat production technology adoption. To analyze quantitative data, descriptive statistical techniques such as frequencies, mean, percentage, minimum, and maximum were employed.

The adoption level of improved bread wheat production technology was analyzed by formulating an adoption index. Many authors such as Abubakar et al. (2016), Fitsum (2016), and Alemu (2010) calculated adoption index by adding up the adoption of each practice and by dividing the number of adopting practices for each household head. According to Rogers (1983), Adoption is a decision to make full use of an innovation at the best appropriate course of action available.

For multiple practices, there are two options for measuring adoption:

(i) Adoption index: measures the extent of adoption at the time of the survey or

(ii) Adoption quotient: measures the degree or extent of use with reference to the optimum possible without taking time into consideration. In this study, the first option was employed. Accordingly, the adoption index, which shows to what extent the household head has adopted the technology packages were calculated using the following formula:

$\mathrm{AI}_{\mathrm{i}}=\quad \sum\left[\frac{\mathrm{AWi}}{\mathrm{TAi}}+\frac{\mathrm{SRAi}}{\mathrm{RSR}}+\frac{\mathrm{AFi}}{\mathrm{AFR}}+\frac{\mathrm{AWRi}}{\mathrm{TAWi}}+\frac{\mathrm{APF}}{\mathrm{RPF}}\right] / \mathrm{NP}$

Where:

$\mathrm{Al}_{\mathrm{i}}=$ adoption index of the $\mathrm{i}^{\text {th }}$ farmer

$\mathrm{AW}_{\mathrm{i}}=$ area under improved variety of wheat of the $\mathrm{i}^{\text {th }}$ farmer

$\mathrm{TA}_{\mathrm{i}}=$ total area allocated for wheat production (improved variety + local variety, if any) of the $\mathrm{i}^{\text {th }}$ farmer

$\mathrm{SRA}_{\mathrm{i}}=$ seeding rate applied per hectare of $\mathrm{i}^{\text {th }}$ farmer

$\mathrm{RSR}=$ recommended seeding rate per hectare.

$\mathrm{AF}_{\mathrm{i}}=$ amount of fertilizer applied per hectare by $i^{\text {th }}$ farmer

$\mathrm{AFR}_{\mathrm{i}}=$ amount of fertilizer recommended for application per hectare for improved bread wheat

$A W R_{i}=$ area covered by row planting of the $i^{\text {th }}$ farmer

$\mathrm{TAW}_{\mathrm{i}}=$ total area covered by wheat production (row planting + broadcasting) of the $\mathrm{i}^{\text {th }}$ farmer

$\mathrm{APF}=$ applied frequency of plowing the farm

$\mathrm{RPF}=$ recommended frequency of plowing the farm.

$\mathrm{NP}=$ number of practices

Another analytical tool used in this study was Tobit model. Tobit model was used to identify the factors determining the improved bread wheat production technology adoption and the intensity of adoption. The Tobit model is an extension of the probit model, and it is really one approach to dealing with the problem of censored data. The farmer may adopt only some part of the recommended improved bread wheat production technologies on their farms. Thus, the Tobit model is more appropriate to give reliable output of both discrete and continuous variable combinations.

It is one of the approaches dealing with the problem of censored data (Johnston and Dandiro, 1997). The Tobit model is best from other binary regression models because binary models attempt to explain the probability of adoption of agricultural technologies by farm households rather than the level or extent of adoption. However, adoption of improved technology alone is not sufficient enough since improvement in production and productivity of farm households depends not only on adoption but also on the intensity of use of the technology. A strictly binary variable is often not sufficient for evaluating the extent of adoption (Feder et al., 1985). In such cases, the Tobit model, which has both discrete and continuous parts, is appropriate because it handles both the probability and level of adoption at the same time.

Many researchers have employed the Tobit model to identify factors affecting adoption and intensity of adoption of improved agricultural technologies. For instance, Abubakar et al., (2016), and Fitsum (2016) studied 
the title of adoption of production technologies by lowland rice farmers, analysis of the factors affecting soybean production technology, assessment of factors affecting adoption of wheat technologies and its impact and adoption of improved sweet potato varieties, respectively.

The specification of the Tobit model is shown below in equation (1). This model was chosen because it has an advantage over other adoption models (LPM, Logistic, and Probit) in that it reveals both the probability of adoption and intensity of use improved bread wheat production technology. Following Maddala (1992), Amemiya (1985), and Johnston and Dandiro (1997), the Tobit model for the continuous variable adoption index, can be defined as:

$\mathrm{AI}_{\mathrm{i}}^{*}=\beta_{0}+\beta_{1} \mathrm{X}_{\mathrm{i}}+\mathrm{U}_{\mathrm{i}}$

$\mathrm{AI}_{\mathrm{i}}=\mathrm{AI}_{\mathrm{i}}^{*}$ if $\beta_{0}+\beta_{1} \mathrm{X}_{\mathrm{i}}+\mathrm{U}_{\mathrm{i}}>0$

Where:

$=0$, if $\beta_{0}+\beta_{1} X_{i}+U_{i} \leq 0$

$\mathrm{AI}_{\mathrm{i}}{ }^{*}=$ the latent variable and the solution to utility maximization problem of extent of adoption subjected to a set constraints per household and conditional on being above contain limit,

$\mathrm{AI}_{\mathrm{i}}=$ adoption index for the $\mathrm{i}^{\text {th }}$ farmer

$\mathrm{X}_{\mathrm{i}}=$ vector of factors affecting adoption and extent of adoption

$\mathrm{B}_{\mathrm{i}}=$ vector of unknown parameters, and

$\mathrm{U}_{\mathrm{i}}=$ the error term, which is normally distributed mean 0 and variance $\sigma^{2}$.

The model parameters are estimated by maximizing the Tobit likelihood function in the following form (Maddala, 1997 and Amemiya, 1985)

$$
\mathrm{L}=\prod_{A l_{i}^{*}>0} \frac{1}{\sigma} f\left(\frac{A I{ }_{i}-\beta_{i} X_{i}}{\sigma}\right) \prod_{A l_{i}^{*} \leq 0} \mathrm{~F}\left(\frac{-\beta_{i} X_{i}}{\sigma}\right)
$$

where $f$ and $\mathrm{F}$ are, respectively, the density function and cumulative distribution function of

$\Pi$

\section{$\Pi$}

AIi * ${ }^{A I} \leq 0$ means the product over those $\mathrm{i}$ for which AIi $* \leq 0$, and $\quad A^{A}>0$ means the product over those $\mathrm{i}$ for which AIi $*>0$

An econometric software known as "Limdep" was employed to run the Tobit model. It may not be sensible to interpret the coefficients of a Tobit in the same way as one interprets coefficients in an uncensored linear model (Johnston and Dinardo, 1997). Hence, one has to compute the derivatives of the estimated Tobit model to predict the effects of changes in the explanatory variables. As cited in Maddala (1997), Johnston and Dinardo (1997), Nkonya et al., (1997), and McDonald and Moffit (1980) proposed the following techniques to decompose the effects of explanatory variables into adoption and intensity effects. Thus change in Xi (explanatory variables) has two effects.

It affects the conditional mean of $\mathrm{AIi} *$ in the positive part of the distribution, and it affects the probability that the observation would fall in that part of the distribution. Similarly, in this study, the marginal effect of explanatory variables was estimated as follows:

1 ). The marginal effect of an explanatory variable on the expected value of the dependent variable is $\frac{\partial \mathrm{E}(\mathrm{ALi})}{\partial \mathrm{Xi}}=\mathrm{F}(\mathrm{Z}) \beta$

where $\beta \mathrm{iXi} / \sigma$ is denoted by $z$, following Maddala (1997):

2 ). The change in the probability of adopting a technology as independent variable $\mathrm{Xi}$ changes is $\frac{\partial \mathrm{F}(\mathrm{Z})}{\partial \mathrm{Xi}}=\mathrm{F}(\mathrm{Z}) \beta \mathrm{i} / \sigma$

$3)$. The change in the intensity of adoption with respect to a change in the explanatory variable among adopters is: $\frac{\partial E\left(\frac{A L i}{A L i *}>0\right)}{\partial X i}=\beta i\left[1-Z \frac{f(z)}{F(z)}-\left(\frac{f(z)}{F(z)}\right)^{2}\right.$

where $\mathrm{F}(\mathrm{z})$ is the cumulative normal distribution of $\mathrm{Z}, f(\mathrm{z})$ is the value of the derivative of the normal curve at a given point (i.e., unit normal density), $\mathrm{Z}$ is the $\mathrm{Z}$-score for the area under normal curve, $\beta$ is a vector of Tobit maximum likelihood estimates, and $\sigma$ is the standard error of the error term. Before running the Tobit model, all the hypothesized explanatory variables were checked for the existence of the multi-collinearity problem.

There are two measures that are often suggested to test the existence of mulit-collinearity. These are the variance inflation factor (VIF) for association among the continuous explanatory variables and contingency coefficients for dummy variables. In this study, variance inflation factor (VIF) and contingency coefficients were used to test the mulit-collinearity problem for continuous and dummy variables, respectively.

According to Maddala (1992), VIF can be defined as: VIF $(\mathrm{Xi})=\frac{1}{1-R^{2}}$ where $\mathrm{R}_{\mathrm{i}}{ }^{2}$ is the

squared multiple correlation coefficient between $\mathrm{Xi}$ and the other explanatory variables. The larger the value of VIF, the more troublesome it is. As a rule of thumb, if the VIF of a variable exceeds 10 (this will happen if $R^{2}$ 
exceeds 0.95 ), that variable is said to be highly collinear (Gujarati, 1995).

Similarly, contingency coefficients were computed for dummy variables using the following formula:

C.C $=\sqrt{\frac{X^{2}}{n+X^{2}}}$

where, CC is the contingency coefficient, $\chi^{2}$ is the chi-square value, and " $n$ " is the total sample size. For dummy variables if the value of contingency coefficient is greater than 0.75 , the variable is said to be collinear (Healy, 1984, as cited in Mesfin, 2005).

\section{RESULTS AND DISCUSSION}

\subsection{General Description of Socio-Economic Characteristics of Respondents}

The average age of the sample households was 48.12 years with a standard deviation of 10.11 . The minimum age was 26 years, while the maximum was 75 years. The average farmland size was 1.02 hectares. The minimum and maximum land sizes owned by sample households were 0.25 and 2.5 hectares respectively. The minimum livestock holding was 0.026 and the maximum was 12.21 in TLU. The average labor availability in terms of man equivalent for the sampled household was 4.67, with a standard deviation of 1.13 (Table 1).

Table 1: Socio-economic characteristics of respondents

\begin{tabular}{llllll}
\hline Variable & Unit & Mean & Std.D & Min. & Max. \\
\hline Age & Years & 48.12 & 10.11 & 26 & 75 \\
Land size owned & Ha. & 1.02 & 0.49 & 0.25 & 2.5 \\
Livestock holding & TLU & 5.12 & 2.17 & 0.026 & 12.21 \\
Active labor force & man equivalent & 4.67 & 1.13 & - & - \\
\hline
\end{tabular}

As the study results indicate, out of 168 sampled household heads, 135 (80.4\%) were male. Regarding level of education, more than half $110(65.5 \%)$ of the respondents were not educated (Table 2$)$.

Table 2: Socio-Demographic Characteristics of the Respondents

\begin{tabular}{llll}
\hline Variable & Response & Freq. & \% \\
\hline Sex & Male & 135 & 80.4 \\
& Female & 33 & 19.6 \\
\hline Education & Cannot read and write & 65 & 38.7 \\
& Can read and write & 45 & 26.8 \\
& Grade 1-4 (1 $1^{\text {st }}$ cycle) & 36 & 21.4 \\
& Grade 5-8 (2 $2^{\text {cy }}$ cycle) & 14 & 8.3 \\
& Grade 9-10 (High school) & 5 & $3 \%$ \\
& Grade 11-12 (Preparatory) & 2 & 1.2 \\
& College diploma \& above & 1 & 0.6 \\
\hline
\end{tabular}

\subsection{Adoption of Improved Bread Wheat Production Technology and Intensity of Adoption}

The level of adoption of improved bread wheat production technology for each household head was different for many reasons. One-way ANOVA analysis revealed that there was a significant mean difference $(\mathrm{F}=1644.090, \mathrm{P}=$ 0.000 ) among the adoption index scores of the four adoption categories at the $1 \%$ significance level, which indicates variation in level of adoption among sampled household heads. The result of the mean adoption index categories of household heads is indicated in Table 3 below.

Table 3: Distribution of household heads based on adoption level of the technology

\begin{tabular}{|c|c|c|c|c|c|}
\hline Adoption categories & $\mathrm{N}$ & $\%$ & $\begin{array}{l}\text { Adoption index } \\
\text { range }\end{array}$ & Mean adoption index & SD \\
\hline Non-adopters & 37 & 22.0 & 0 & 0.00 & 0.00 \\
\hline Low & 52 & 31.0 & $0.21-0.57$ & 0.52 & 0.07 \\
\hline Medium & 45 & 26.8 & $0.58-0.69$ & 0.61 & 0.02 \\
\hline High & 34 & 20.2 & $0.70-0.93$ & 0.79 & 0.06 \\
\hline Total & 168 & 100.0 & $0-1$ & 0.48 & 0.28 \\
\hline
\end{tabular}

*** The mean difference is significant at $1 \%$ level of probability.

\subsubsection{DAP/NPS fertilizer application rate}

Fertilizer is an important input for the increment of production and productivity of crop yield. The study revealed that most farmers use below the recommended amount of fertilizer per hectare, and they use NPS fertilizer instead of DAP. Generally, the mean rate of fertilizer application by household heads was $73.64 \mathrm{~kg} / \mathrm{ha}$. Regarding the four of adoption categories, the mean DAP/NPS fertilizer application rates of Non-adopters, low, medium and high adopters was $0.00 \mathrm{~kg} / \mathrm{ha}, 72.35 \mathrm{~kg} / \mathrm{ha}, 72.01$, and $77.77 \mathrm{~kg} / \mathrm{ha}$, respectively.

Analysis of variance $(\mathrm{F}=1.254, \mathrm{P}=0.289)$ revealed that there was no significant mean difference among 
adoption categories (Table 4).

Table 4: Mean application rate of DAP/NPS fertilizer in $\mathrm{kg} / \mathrm{ha}$ in each category

\begin{tabular}{lllll}
\hline Adoption categories & $\mathrm{N}$ & $\%$ & Mean & SD \\
\hline Non-adopters & 37 & 22.0 & 0.00 & 0.00 \\
Low & 52 & 31.0 & 72.35 & 17.46 \\
Medium & 45 & 26.8 & 72.01 & 18.64 \\
High & 34 & 20.2 & 77.77 & 16.75 \\
\hline Total & 168 & 100.0 & 73.64 & 17.73 \\
\hline \multicolumn{4}{l}{} \\
\hline
\end{tabular}

*** The mean difference is significant at $1 \%$ level of probability.

\subsubsection{UREA fertilizer application rate}

According to the zonal office of agriculture, the recommended rate of application for UREA fertilizer is $150 \mathrm{~kg} / \mathrm{ha}$, and two thirds of this will be applied at planting time, and the remaining one third will be applied after 21 days of planting. However, the results of the study revealed that all of the adopters' categories were applied less than the recommended amount (average $68.43 \mathrm{~kg} / \mathrm{ha}$ ). Regarding to fertilizer application rate, one-way ANOVA analysis of variance also revealed that there was a statistically significant mean difference among adoption categories $(\mathrm{F}=$ 86.020, $\mathrm{P}=0.000$ ) at $1 \%$ probability level (Table 5).

During FGD, farmers also confirmed that due to the high price of fertilizer they were forced to use less than the recommended amount. The focus group participants were critically indicated that the price of fertilizer was rising from time to time, but price for wheat product was falling dawn.

Table 5: Mean UREA fertilizer rate applied in (kg/ha) by each adopter category

\begin{tabular}{lllll}
\hline Adoption categories & $\mathrm{N}$ & $\%$ & Mean & SD \\
\hline Non-adopters & 37 & 22.0 & 0.00 & 0.00 \\
Low & 52 & 31.0 & 59.80 & 29.71 \\
Medium & 45 & 26.8 & 70.80 & 23.90 \\
High & 34 & 20.2 & 78.50 & 24.91 \\
\hline Total & 168 & 100.0 & 68.43 & 27.49 \\
\hline \multicolumn{4}{l}{} \\
\hline
\end{tabular}

*** The mean difference is significant at $1 \%$ level of probability.

3.2.3 Improved bread wheat varieties used by household heads

Improved varieties of bread wheat will give high yields whenever planted under the recommended management practices. Of the 131 bread wheat production technology adopters household heads almost all $129(98.5 \%)$ of them used improved varieties (Table 6).

Table 6: Improved bread wheat varieties used by adopter household heads

\begin{tabular}{lll}
\hline Type of varieties used & Frequency & $\%$ \\
\hline Non-improved variety (Local) & 2 & 1.5 \\
Shorima & 72 & 55 \\
Kekeba & 13 & 9.9 \\
Hidasie & 22 & 16.8 \\
Ogolicha & 13 & 9.9 \\
Ogana & 9 & 6.9 \\
\hline Total & 131 & 100.0 \\
\hline
\end{tabular}

\subsubsection{Frequency of cultivating the farm}

Appropriate farmland cultivation is one of the management practices to improving the productivity of wheat crops. According to the Agricultural Transformation Agency (ATA) and MoA (2014) the recommended frequency of plowing for wheat production is 5-6 times. However, the study revealed that the mean total number of plowing 3.73 times with a standard deviation of 1.05 (Table 7). This indicates that farmers in the study area plow less than the recommended number of plowing, and which in turn affects the yield of wheat production in the study area. One-way ANOVA analysis also indicated the presence of a significant mean difference among adoption categories at the $1 \%$ level $(\mathrm{F}=281.967, \mathrm{P}=0.000)$. 
Table 7: Distribution of adopter categories by frequency of plowing the farm

\begin{tabular}{lllll}
\hline Adoption categories & $\mathrm{N}$ & $\%$ & Mean & SD \\
\hline Non-adopters & 37 & 22.0 & 0.00 & 0.00 \\
Low & 52 & 31.0 & 4.71 & 0.97 \\
Medium & 45 & 26.8 & 4.73 & 0.98 \\
High & 34 & 20.2 & 4.97 & 1.05 \\
\hline Total & 168 & 100.0 & 3.73 & 2.17 \\
\hline \multicolumn{5}{l}{}
\end{tabular}

*** The mean difference is significant at $1 \%$ level of probability.

3.2.5. Farmland covered by row planting

To improve the productivity of wheat, practicing improved agronomic practice is a crucial issue. Row planting is an essential component of the adoption of improved wheat production technology.

The average area covered by row planting in hectare of each adopter category was $0,0.170,0.138$, and 0.632 for non-adopters, low, medium, and high adopter categories, respectively. Analysis of variance showed that there was a significant mean difference among the adoption categories $(\mathrm{F}=47.696, \mathrm{P}=0.000)$ in relation to adoption level of row planting at the $1 \%$ significance level (Table 8 ).

The results of focus group discussion indicate that, currently wheat row planting was practiced manually and the application method is more labor intensive. As a result, at planting time at least three human power was required, which means the first person is making a row, the second putting seed in the row, and the third one is applying fertilizers. It was a labor-intensive practice, and because of this, those households with more active labor force relatively be more adopters of the technology.

Table 8: Area covered by row planting.

\begin{tabular}{lllll}
\hline Adoption categories & $\mathrm{N}$ & $\%$ & $\begin{array}{l}\text { Mean \% of farmland covered } \\
\text { by row planting (ha) }\end{array}$ & SD \\
\hline Non-adopters & 37 & 22.0 & 0 & 0.00 \\
Low & 52 & 31.0 & 17.0 & 0.17 \\
Medium & 45 & 26.8 & 13.8 & 0.22 \\
High & 34 & 20.2 & 63.2 & 0.40 \\
\hline Total & 168 & 100.0 & 21.8 & 0.32 \\
\hline \multicolumn{5}{r}{$\mathrm{F}=47.696^{* * * ;}$ P-value $=0.000$} \\
\hline
\end{tabular}

*** The mean difference is significant at $1 \%$ level of probability.

3.2.7. Seeding rate of row the planting method

Applying the recommended level of seeding rate is an important practice in wheat production. Using either higher or lower seed rates other than the recommended rate will lead to low productivity.

The recommended seeding rate for improved bread wheat in row planting is $100 \mathrm{~kg} / \mathrm{ha}$ (HZANRDD, 2015 and MoA, 2014). The results of the study indicates that, on average $0.00,18.79,13.99$, and $74.17 \mathrm{~kg} / \mathrm{ha}$ of seed was used by non-adopters, low, medium, and high adopters, respectively (Table 9). This shows that all of the household heads in the study area use below the recommended rate of seed. On the other hand, the one-way ANOVA analysis also revealed that there was a significant mean difference among adopter categories at the $1 \%$ significance level $(\mathrm{F}=109.653, \mathrm{P}=0.000)$.

Table 9: Seeding rate applied in row planting per hectare

\begin{tabular}{lllll}
\hline Adoption categories & $\mathrm{N}$ & $\%$ & Mean & SD \\
\hline Non-adopters & 37 & 22.0 & 0.00 & 0.00 \\
Low & 52 & 31.0 & 18.79 & 18.12 \\
Medium & 45 & 26.8 & 13.99 & 18.94 \\
High & 34 & 20.2 & 74.17 & 26.78 \\
\hline Total & 168 & 100.0 & 31.52 & 32.85 \\
\hline \multicolumn{4}{l}{} \\
\hline
\end{tabular}

*** The mean difference is significant at $1 \%$ level of probability.

\subsubsection{Seeding rate of broadcasting method}

It was indicated that adopters in the low and medium categories 97 (57.8\%) were sawn their farm by broadcasting methods of planting, which uses $50 \mathrm{~kg}$ of extra seed than the recommended rate of row planting. The recommended rate of seeding by broadcasting is $150 \mathrm{~kg} / \mathrm{ha}$ (HZANRDD, 2016 and MoA, 2014). However, on average 0.00 , $88.86,100.33$, and $24.38 \mathrm{~kg} /$ ha of seed was used by non-adopters, low, medium, and high adopters, respectively. One-way ANOVA revealed a significant mean difference among adopter categories at the $1 \%$ significance level $(\mathrm{F}=51.731, \mathrm{P}=0.000)$, shows that all adopters apply lower than the recommended seeding rate (Table 10$)$. 
Table 10: Seeding rate applied by broadcasting per hectare

\begin{tabular}{lllll}
\hline Adoption categories & $\mathrm{N}$ & $\%$ & Mean & $\mathrm{SD}$ \\
\hline Non-adopters & 37 & 22.0 & 0.00 & 0.00 \\
Low & 52 & 31.0 & 88.86 & 32.81 \\
Medium & 45 & 26.8 & 100.33 & 34.17 \\
High & 34 & 20.2 & 24.38 & 40.80 \\
\hline Total & 168 & 100.0 & 76.75 & 47.35 \\
\hline \multicolumn{4}{l}{} \\
\hline
\end{tabular}

*** The mean difference is significant at $1 \%$ level of probability.

\subsection{Results of the Econometric Model}

\subsubsection{Factors influencing the adoption of improved bread wheat production technology}

A total of 15 variables were hypothesized to influence the adoption of improved bread wheat production technology. The model output indicated that eight of the variables influenced the adoption of the technology (Table $11)$.

Table 11: Maximum likelihood estimates of the Tobit model.

\begin{tabular}{lllll}
\hline Variables & $\begin{array}{l}\text { Estimated } \\
\text { Coefficient }\end{array}$ & Standard error & t-ratio & p-value \\
\hline CONSTANT & -0.1434411 & 0.2155197 & -0.67 & 0.507 \\
AHH & -0.0023965 & 0.0030491 & -0.79 & 0.433 \\
SEXHH & 0.992728 & 0.0466068 & $2.13^{* *}$ & 0.035 \\
EDUCLHH & 0.455793 & 0.0156294 & $2.92^{* * *}$ & 0.004 \\
ACTIVELF & 0.0354971 & 0.155588 & $2.28^{* *}$ & 0.024 \\
FARME & 0.0010283 & 0.0037137 & 0.28 & 0.782 \\
TOTALLH & 0.103418 & 0.0423691 & $2.44^{* *}$ & 0.016 \\
TOTALNLS & -0.0003619 & 0.0086992 & -0.04 & 0.967 \\
OFFINCOM & -0.0053114 & 0.0397721 & -0.15 & 0.877 \\
ACCTOC & 0.0678855 & 0.0397721 & $1.71 *$ & 0.090 \\
FRIQUEC & 0.0449516 & 0.0142642 & $3.15 * * *$ & 0.002 \\
FRIQUFVD & 0.0211056 & 0.0136948 & 1.54 & 0.125 \\
TRAINING & 0.0477908 & 0.0145968 & $3.27 * * *$ & 0.001 \\
MASEXP & 0.0122459 & 0.0055434 & $2.21 * *$ & 0.029 \\
PRISEED & -0.0148884 & 0.0280117 & -0.53 & 0.596 \\
PRIFERTI & -0.0398789 & 0.0400022 & -1.00 & 0.327 \\
PARSON & 0.0068171 & 0.0069286 & 0.98 & 0.327 \\
SIGMA & 0.210089 & 00.0138717 & & \\
\hline
\end{tabular}

Source: model output, $* * *, * *$, and $*$ significant at the $1 \%, 5 \%$, and $10 \%$ probability levels.

Log likelihood $=-16.861109$

Pseudo $\mathrm{R}^{2}=0.8187$

$\mathrm{P}=0.0000$

Obs. Summary: 37 left-censored observations at adoption index $<=0$.

131 uncensored observations

0 right-censored observations

3.3.2. Intensity of adoption of improved bread wheat production technology

In this section, we present the results of our analysis of the intensity of adoption to ensure the consistency of results. Interestingly, all of the variables that were significant in determining adoption were also significant in determining the intensity of adoption of improved bread wheat production technology (Table 12). 
Table 12: Model result of the intensity of adoption

\begin{tabular}{lllll}
\hline Variable & dy/ex & Std.err. & $\mathrm{Z}$ & $\mathrm{P}>/ \mathrm{Z} /$ \\
\hline AHH & -.1153295 & .1467401 & -0.79 & 0.432 \\
SEXHH & .0797728 & .0374519 & $2.13^{* *}$ & 0.033 \\
EDUCLHH & .0984838 & .0337706 & $2.92^{* * *}$ & 0.004 \\
ACTIVELF & .166118 & .0728115 & $2.28^{* *}$ & 0.023 \\
FARME & .0242564 & .0876047 & 0.28 & 0.782 \\
TOTALLH & .1056341 & .043277 & $2.44^{* *}$ & 0.015 \\
TOTALNLS & -.0018482 & .0444213 & -0.04 & 0.967 \\
OFFINCOM & -.0026241 & .016988 & -0.05 & 0.877 \\
ACCTOC & .0464692 & .027225 & $1.7^{*}$ & 0.088 \\
FRIQUECO & .1220115 & .0387172 & $3.15^{* * *}$ & 0.002 \\
FRIQUFVD & .0467339 & .0303241 & 1.54 & 0.123 \\
TRAINING & .0859097 & .0262394 & $3.27^{* * *}$ & 0.001 \\
MASEXP & .0589697 & .0266942 & $2.21^{* *}$ & 0.027 \\
PRISEED & -.0381959 & .0718633 & -0.53 & 0.595 \\
PRIFERTI & -.1094295 & .1097679 & -1.00 & 0.319 \\
PARTSON & .0371289 & .0377361 & 0.98 & 0.325 \\
\hline
\end{tabular}

Source: model output, $* * *, * *$, and $*$ significant at the $1 \%, 5 \%$, and $10 \%$ probability levels.

Sex of household head: The model output indicated that the sex of the household head was one of the determinants of bread wheat production technology adoption. The Tobit model output shows a positive and significant influence on the adoption of improved bread wheat production technology at the $5 \%$ significance level. This indicates that male headed households have more access to get information on technology adoption than female-headed households. This result is consistent with the findings of Berihanu et al., (2014).

Education level of household head: as it was hypothesized, education level of the household head affected the adoption and adoption intensity of improved bread wheat production technologies positively and significantly at the $1 \%$ of significance level.

This is due to the fact that educated person can gain better skill, experience, knowledge, and this again helps them to adopt improved bread wheat production technology. Household heads with relatively higher education levels are faster to accept new technologies. Therefore, education level and adoption of new agricultural technologies have a positive relationship. This result is consistent with the findings of Mesay et al. (2013), Tolesa et al. (2014), Leake and Adam (2015), and Ejegayehu (2016).

Active labor force in man equivalent: as it was expected, active labor forces in man equivalent affects the adoption of improved bread wheat technologies. Households with more number of active labor forces in man equivalent adopt improved bread wheat production technologies than those households with a low number of active labor forces.

Households with a high number of active labor force can undertake agricultural activity over time and effectively manage the wheat fields especially at the time of land preparation, row planting, and harvesting. This result is similar to the finding of Leake and Adam (2015).

Total farmland size: Land is the most important resource and base for any economic activity in rural areas. Rural households with higher land size have a better livelihood than those less land holding size households. The results of this study indicate that, a total farmland size has a positive and significant relationship with the adoption and intensity of adoption improved bread wheat production technologies. This result is consistent with the findings of Berihanu et al. (2014) and Mesay et al. (2013).

Access to credit: access to credit service is one way of improving household heads' adoption level of new agricultural technologies. The Tobit model result indicates that access to credit affects the adoption of improved bread wheat production technology in the study area positively and significantly. In the study area, there is no access to credit in cash, but there is access to credit of fertilizer in kind by down payment of $50 \%$.

Extension contact: Extension contact influence positively and significantly the adoption of improved bread wheat production technologies. This indicates that extension agent visits for the dissemination of information and advisory services would give the household heads more confidence to sustain the use of new agricultural technology. This result complements Tolesa (2015), and Berihanu et al., (2014).

Participation in Training: Training enhances agricultural production skills, knowledge, and experiences of household heads. In this study, training has shown a positive and significant influence on the adoption and intensity of adoption of improved bread wheat production technologies. This implies that attention has to be given to farmers to participate in training the introduction of new technologies.

Mass media exposure: The adoption process of agricultural technologies depends primarily on the availability of information and on the willingness and ability of the farmers. This study also confirms that mass media exposure has a positive relationship with the adoption and intensity of adoption of improved bread wheat production 
technologies.

3.3.3 Marginal effects of significant explanatory variables on the probability of adoption and intensity of adoption

From the identified variables, some variables have a high influence on improved bread wheat production technology adoption, while others have less influence in the decision making of farm household heads. The result of the Tobit model was used to assess the effects of changes in the explanatory variable on adoption and intensity of adoption; the results indicated in Table 14

Table 13: Marginal effects of significant variables

\begin{tabular}{llll}
\hline Variables & $\begin{array}{l}\text { Change in the probability of } \\
\text { adoption }\end{array}$ & $\begin{array}{l}\text { Change in intensity } \\
\text { adoption }\end{array}$ & of \\
\hline SEXHH & 0.0992728 & 0.0797728 & 0.0992728 \\
EDUCLHH & 0.0455793 & 0.0984838 & 0.0455793 \\
ACTIVELF & 0.0354971 & 0.166118 & 0.0354971 \\
TOTALLH & 0.103418 & 0.1056341 & 0.103418 \\
ACCTOC & 0.0678855 & 0.0464692 & 0.0678855 \\
FRIQUEC & 0.0449516 & 0.1220115 & 0.0449516 \\
TRAINING & 0.0477908 & 0.0859097 & 0.0477908 \\
MASEXP & 0.0122459 & 0.0589697 & 0.0122459 \\
\hline
\end{tabular}

The model output indicates that being male headed households increases the probability of adoption and intensity of adoption of improved bread wheat production technologies by $9.9 \%$ and $7.9 \%$, respectively, (all other factors kept constant).

The estimated influences of education increase by 1 level of education have a positive change in the probability of adoption and intensity use of improved bread wheat production technologies by $4.5 \%$ and $9.8 \%$, respectively, (other factors kept constant). Education level was measured in categories as farmers that cannot read and write, read and write, grades 1-4, grade 5-8, grades 9-10, grades 11-12, and college diploma and above. Hence, a change in one categorical level of education enhances the probability of adoption and intensity use of improved bread wheat production technologies.

The marginal effect result shows that a unit increase in active labor force increases the probability of adoption and intensity use of improved bread wheat production technologies by $3.5 \%$ and $16 \%$, respectively, (all other factors remain constant). The results indicate that households with a high number of active labor force can undertake the agricultural activity on time and effectively manage the wheat fields, especially land preparation, row planting, and harvesting time.

The marginal effect result also shows that increasing farmland size by one hectare promotes the probability adoption and intensity use of improved bread wheat production technologies by $10.3 \%$ and $10.5 \%$, respectively, (all factors were kept constant).

With regard to this variable, even though there is no way to increase the size of farmers' landholding in the study area. With regard to this variable, the essential intervention in the area was to convince farmers to use intensive agricultural practices by using the recommended level of bread wheat production technologies on their own plot of land.

Result of analysis of marginal effects shows that having access to credit service increases the probability of adoption and intensity use of improved bread wheat production technologies by $6.7 \%$ and $4.6 \%$, respectively. On the other hand, a unit increase in the frequency of contact with the extension agent increases the probability of adoption and intensity of use of technologies by $4.4 \%$ and $12.2 \%$, respectively, (all other factors were kept constant). The fact that access to extension services affects the adoption of improved bread wheat production technology positively and significantly; this implies the important role of extension personnel played in order to change farmers' attitudes and create awareness of the importance of improved bread wheat production technologies.

Regarding training, a unit of training increases the probability of adoption and intensity use of improved bread wheat production technologies increases by $4.7 \%$ and $8.5 \%$, respectively, (all other factors remain constant). Therefore, extension services promote new agricultural technology dissemination and enhance the agricultural productivities of smallholder farmers.

A unit increase in mass media exposure increases the probability of adoption and intensity use of improved bread wheat production technologies by $1.2 \%$ and $5.8 \%$, respectively, (all other factors remain constant). The result indicates that households with more exposure to mass media can get current new agricultural information and practices.

\section{CONCLUSION AND RECOMMENDATION}

4.1 Conclusion

Improving production and productivity of improved bread wheat is a key issue as a means of livelihood and 
improving food security. This study analyzed the improved bread wheat production technology adoption at the farm level by collecting data from 168 household heads.

From the findings of this study, variation in adoption and intensity of adoption of recommended bread wheat production technologies among sampled households were found to be affected by different factors. The results of the econometric model indicate that the relative influence of different variables on the probability and intensity use of improved bread wheat production technologies. Thus, the sex of household heads, level of education, active labor force of household members, total farmland size, access to credit, frequency of contact with extension agents, participation in training, and exposure to mass media were found to have a significant influence on the probability and intensity of adoption of improved bread wheat production technology.

\subsection{Recommendations}

Based on the above conclusion, the following recommendations were forwarded: It is crucial to give special attention empowering women farmers because there was low participation of women in technology adoption. Household heads with relatively higher education levels and owning larger size of farmland were faster to adopt new technologies. Therefore, it would be advisable to use those household heads as an exemplary when introducing new technologies.

Active labor force was an important factor in technology adoption from land preparation up to the harvesting period. This necessitates strengthening the existing and forming new farmer groups to use the labor they have efficiently in their farm.

Intensive advisory services would have a great impact on increasing the improved bread wheat production technology adoption. Therefore, the government and other stakeholders who are working in the agriculture sector should support and strengthen extension workers to enhance the adoption of technologies among farmers. Facilitating access to credit services and participating farmers in training activities has to be given attention in order to enhance the adoption of new technologies. This study revealed that mass media exposure has a positive relationship with the adoption and intensity of adoption of improved bread wheat production technologies. Therefore, important, relevant, and timely information needed to be communicated to farmers through the mass media.

\section{References}

Abubakar H, Isa N, Abdullahi A and Yahaya G. (2016). Adoption of Production Technologies by Lowland Rice Farmers in Lavun Local Government of Niger State, Nigeria. International Journal of Agricultural Extension. 04(01) Pp. 49-56.

Adegbidi, A., Mensah, R., Vidogbena, F., \& Agossou, D. (2012). Determinants of ICT use by rice farmers in Benin : from the perception of ICT characteristics to the adoption of the technology. Journal of Research in International Business and Management, 2(11), 273- 284.

Alemu ZG, Oosthuizen LK, Van Schalkwyk HD. (2010). Agricultural development policies of Ethiopia since 1957. University of the Free State.

Amemiya, T. (1985). Advanced Econometrics. T.J. Press, Pad stow Ltd: Great Britain.

Berihanu K. Hailu, Bihon K. Abrha and Kibrom A. Woldegiorgis. (2014). Adoption and Impact of Agricultural Technologies on Farm Income. Evidence from Southern Tigray, Ethiopia. International Journal of Food and Agricultural Economics. 2(4): Pp. 91-106.

CSA (Central Statistics Agency) (2016). Agricultural Sample Survey: Area and Production of Major Crops. 2016. Addis Ababa.14 pp.

Deribe, K. (2011). Agricultural Information Networks of Farm woman In Southern Ethiopia: The role of agricultural extension. GmbH \& Co. KG Saarbrucken, Germany: LAP Lambert Academic Publishing.

ECXA (Ethiopia Commodity Exchange Authority) (2008).Understanding Wheat: A Review of Supply and Marketing Issues. 2008. Addis Ababa. 4 pp.

Feder G., Just.E and Zilberman.D .(1985). Adoption of Agricultural Innovations in Developing Contries: a Survey. Economic Development and Cultural Change.

Fitsum Miruts (2016). Analysis of the Factors Affecting of Soybean Production Technology in Pawe Disrctict, Metekele Zone of Benshangul Gumuz Regional state, Ethiopia. World Scientific News. 53(3): Pp.122-137.

GAIN (Global Agricultural Information Network) ( 2013). Grain and Feed Annual Report. 2013. Ethiopia. 1-5 pp.

GAIN (Global Agricultural Information Network) (2014). Grain and Feed Annual Report. 2014. Ethiopia.4 pp.

Gebreselassie A, Bekele T. (2010). A review of Ethiopian agriculture: roles, policy and small- scale farming systems. Ethiopia and D. R. Congo; 2010.

Gujarati D.N. (1995). Basic Econometrics. $3^{\text {rd }}$ edition, McGraw Hill, Inc., New York.

Johnston, J. and Dandiro, J. (1997). Econometrics Methods, fourth Edition, New York.

Lulit Mitik, Ermias Engeda and Zelalem Hailegiorgis. (2012). Public Investment in Irrigation and Training for an Agriculture-led Development: a CGE Approach for Ethiopia. Addis Ababa, Ethiopia. Pp 58 
Maddala, G. S. (1997). Limited Dependent and Quantitative Variables in Econometrics. Cambridge University Press.

Mcdonald, J.F. and R.A. Moffit, (1980). The Uses of Tobit Analysis. Review of Economics and Statistics 62(2):318-321.

Mesay Y, Teklu T, Adam B (2013). Determinants of Farmers ee Participation Decision on Local Seed Multiplication in Amhara Region, Ethiopia. Int. J. Sci. Res. 2(1):423-430.

Mesfin Astatkie. (2005). Analysis of Factors Influencing Adoption of Triticale and Its Impact, the Case Farta Wereda, Debub Gonder Zone, Amhara Regional State. Unpublished Msc. Thesis, Alemaya University, Ethiopia.

Nkonya.E, Schroeder. T and Norman. D. (1997). Factors Affecting Adoption of Improved Maize Seed and Fertilizer in North Tanzania. Indian j. Agri.econ. 48(1):1-12

Pender, J., \& Gebremedhin, B. (2004). Impact of policy and technologies in dry land agriculture: Evidences from Northern Ethiopia. Crop Science Society of America. Retrieved from http://hdl.handle.net/10568/50696

Ray, G. L. (2001). Extension Communication and Management. India: Naya Prokash press.

Rogers, E. (1983). Diffusion of Innovations: The Free Press, New York.

Tembo, R. (2008). Information and communication technology usage trends and factors in commercial agriculture in the wine industry. CPUT Theses \& Dissertations. Paper 66.

Tolesa Alemu, Bezabih Emana, Jema Haji and Belaineh Legesse. (2014). Impact of Wheat Row Planting on Yield of Smallholders in Selected Highland and Lowland Areas of Ethiopia. International Journal of Agriculture and Forestry, 4(5): Pp. 386-393.

Tolesa Alemu. (2015). Socio-Economic and Institutional Factors Limiting of Wheat Row Planting in Selected Districts of Arsi Zone. Science, Technology and Arts Research Journal, 4(1): Pp. 229-233.

UNDP (United Nation Development Program). (2014). United Nation Program in Ethiopia Annual Report. UNDP, Addis Ababa, Ethiopia. Pp. 1-18.

Welteji, D. (2018). A critical review of rural development policy of Ethiopia : access , utilization and coverage. Agriculture \& Food Security, 1-6. https://doi.org/10.1186/s40066-018- 0208-y 